Vol. 4, No. 4, 2019

\title{
GASEOUS EMISSIONS PURIFICATION WITH THE POLYMER GAS-DISTRIBUTING MEMBRANES APPLICATION
}

\author{
Klaudia Mudrak \\ National Transport University, \\ 1, Omelianovycha-Pavlenka Str., Kyiv , 01010, Ukraine \\ klav@ukr.net
}

https://doi.org/10.23939/ep2019.04.174

Received: 11.09.2019

(C) Mudrak K., 2019

\begin{abstract}
Gas emissions into the atmosphere by chemical, oil and other industries are an environmental threat on a planetary scale. Gas separation membranes can solve production problems. The purpose of the work was the selection and synthesis of polymers with high transmembrane transport parameters. Diaphragm modules based on polyamidoimides were obtained for gas flow separation
\end{abstract}

Key words: gas separation membrane; selectivity; polyamidoimides; membrane module.

\section{Introduction}

Membrane processes are highly efficient methods of dividing mixtures into components. The use of membrane gas separation is able to solve one of the major technical contradictions of "industrial potential growth" "cleanliness of the environment" [1]: they are "nonreactive", or more precisely, "low-reactive". In addition, the simplicity of equipment, cost-effectiveness, longterm operation of gas-separation membranes with unchanged characteristics, the possibility of complete automation of installations cause their widespread use in the chemical industry. Membrane technologies in the pharmaceutical, biotechnological and food industries are also promising [2-6].

The effectiveness of membrane technologies is determined by both the structure and the material of the membrane installations.

Environmental safety and energy conservation issues can be solved, in particular, with the help of polymer membranes.

Membranes based on polyimides were characterized by high selectivity but relatively low permeability of the target component [7-9].

Polyamidoimide (PAI) based membranes have become more effective [10].
The combination of high performance of membranes with their sufficient selectivity is achieved by a suitable polymer structure. For vitreous macromolecular compounds, a kinetic selectivity factor controlled by free volume is essential. In accordance with this concept, a number of polyamidoimide gas separation membranes have been developed based on the imides of tri- and tetracarboxylic acids and diamines, including both bridging groups and bulk substitutes [11]. Of particular interest is the study of PAIs based on cardiac diamines. Their large size and high local stiffness can be distinguished by the properties that depend on the kinetic free volume reserve.

The properties of gas transfer of membranes depend, in particular, on the type of molecular chain aggregation, which is caused by the degree of interaction of associates in the initial reaction solution $[12,13]$. For this purpose, optimal methods for the synthesis of soluble PAI having good gas separation properties were investigated.

Polyamidoimide membranes are made from solutions. Therefore, the properties of the obtained polymers in the dissolved state were investigated.

The coexistence of electron-donor and acceptor centres in polyamide macromolecules determines their characteristic tendency to inter-chain association, which has a decisive influence on their behaviour in solutions and solids [14]. The dependence of the properties of copolyamidoimides (COPAI) in the block and dissolved state on the molecular structure of their macromolecular chain was studied by means of wide-angle and low-angle $\mathrm{X}$-ray diffraction and thermogravimetric analysis.

\section{Experimental part}

\subsection{Materials}

The subject of the study were COPAI based on trimellithimido- $\mathrm{N}$-acetic acid (THIOC), 
diaminodiphenylmethane

(DADPM)

and anilinfluorene (AF).

Synthesis of COPAI was performed in dimethylacetamide (DMAA) at $273 \mathrm{~K}$ for one hour with vigorous stirring of the reaction mixture, and then stirred for another two hours at room temperature. At the end of the reaction, the polymers were planted in water, washed and dried at 353-363 $\mathrm{K}$ to constant weight.

The dependence of the reduced viscosity of the PAI on the ratio of starting materials in the reaction solution is established. The highest molecular weight of the polymer was achieved at $13 \%$ excess of dichloroanhydride. The reaction was carried out in a $20 \%$ solution of DMAA mixture of dichloroanhydride and aromatic diamines.

\subsection{Methods}

The viscosity of PAI solutions was determined in the DMAA on the Ubelode viscometer at a temperature of $298 \mathrm{~K}$.

The effective viscosity of COPAI solutions in DMAA was investigated on a Reotest-2 viscometer (work unit - coaxial cylinders) in the temperature range of $288-368 \mathrm{~K}$ every $10 \mathrm{~K}$ at shear rates of $0.03-1312 \mathrm{c}^{-1}$. The mass content of polymers in the solutions was $3,5,7,10$, 15 and 20 wt. $\%$.

TGA was performed in a nitrogen atmosphere in the temperature range 303-973 K.

The coefficient of permeability $\mathrm{K}$ of a number of standard gases was measured at a temperature of $298 \mathrm{~K}$, on a device based on a chromatograph with a thermal conductivity detector $[15,16]$, with a pressure drop of about $0.1 \mathrm{MPa}$, and a relative error of $20 \%$.
The samples for the study in the form of flat films $30 \mu \mathrm{m}$ thick were obtained by irrigation of $10 \%$ solutions in DMAA on a glass substrate, slow evaporation of the solvent during the day at $298 \mathrm{~K}$ and subsequent vacuuming during the day at $400 \mathrm{~K}$ to constant weight.

\section{Results and discussion}

Membrane modules are typically cylindrical containers filled with hollow polymer fibres arranged in parallel. Such membranes are made of polymer solutions by the method of dry-wet phase inversion.

When the gas mixture is supplied to such module, the target component of the gas mixture having the highest rate of permeation through the membrane wall enters the "submembrane" space. This way the concentration of a particular component of the gas mixture occurs.

Hollow fibre modules are formed in two basic geometric shapes [2-5]. In the first construction the separable mixture is supplied into the space between the hollow fibres and is used, for example, in the systems of hydrogen separation from gas mixtures. The separable mixture is injected into the interfibrous space of the system; the permeate (substances that penetrate the membrane) passes through the fibre wall and exits through the open ends of the fibres.

Another type of hollow module is characterized by the flow of raw material inside the fibres (Fig. 1). The fibres in the modules of this type are open at both ends and the separable mixture circulates through the holes in the fibres. In order to reduce the hydraulic resistance inside the fibres, the diameter is usually larger than that used in modules with the raw material fed into the space between the fibres.

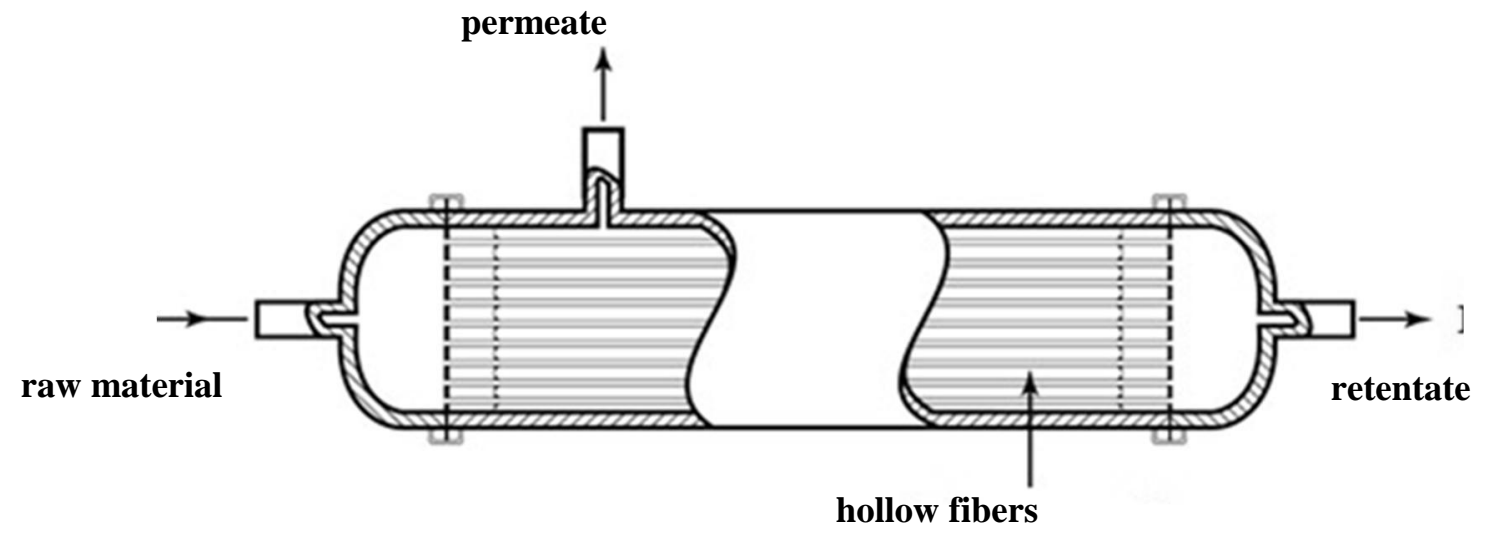

Fig. 1. Diaphragm unit for separating the mixture of gases with raw materials fed inside fibers

The module case has one inlet for the input of the initial mixture and two outlets for the output of the separated components. The separation of the mixture is based on different permeability of oxygen, nitrogen and other components due to the difference of partial pressures on the outer and inner surfaces of the hollow fibre membrane. Gases rapidly penetrating the polymeric membrane-permeate (e.g, $\mathrm{H}_{2}, \mathrm{CO}_{2}, \mathrm{O}_{2}$, water vapour, higher hydrocarbons), enter the fibres and exit through one of the outlet nozzles. Gases that "slowly" penetrate the membrane - retentate (eg, $\mathrm{CO}, \mathrm{N}_{2}, \mathrm{CH}_{4}$ ) exit the membrane module through the second outlet.

Membrane processes are characterized by selectivity and productivity. The process selectivity is usually 
characterized by the magnitude of the partition coefficient. The specific productivity (permeability) of the membranes is expressed by the volume (or mass) of the permeate obtained at a given driving force per time unit from the unit of the area of the working membrane surface.

The volumes of oxygen and nitrogen passing through the membrane are respectively determined by the formulas [6]:

$$
\begin{aligned}
& \mathrm{Vo}=\mathrm{Co} \bullet \mathrm{S} \bullet \Delta \mathrm{P} \bullet \tau, \\
& \mathrm{Va}=\mathrm{Ca} \bullet \mathrm{S} \bullet \Delta \mathrm{P} \bullet \tau,
\end{aligned}
$$

- where $\mathrm{Co}$ and $\mathrm{Ca}$ are the oxygen and nitrogen permeability coefficients, respectively;

- $\mathrm{S}$ is the area of the working surface of the membrane;

- $\Delta \mathrm{P}$ is the pressure difference before and after the membrane;

- $\tau$ is time.

The physical meaning of the coefficients $\mathrm{Co}$ and $\mathrm{Ca}$ is that they, respectively, show the volume of pure oxygen and nitrogen that pass through $1.0 \mathrm{~m}^{2}$ of the membrane per time unit at a pressure difference of 1.0 MPa. The numerical values of the coefficients are determined experimentally.

In modules with raw material fed inside the fibres, it is important to make sure that the fibres are of the same diameter and permeability.

Membranes are classified by porous structure into non-porous (diffusion) and porous. The latter are divided into isotropic and anisotropic, including asymmetric. Anisotropic membranes are characterized by a gradual change in pore diameter in their cross-section, that is, the pore diameter gradually increases from the working to the underlying surface of the membrane. Asymmetric anisotropic membranes are also characterized by an increase in pore diameter from the working to the underlying surface, but in this case, the membrane layers are clearly distinguished, within which the pores are approximately the same and markedly different in size from the pores in the layers above and below them.

Asymmetric hollow fibres have a complex wall structure. The functionality of the membranes defines a thin (0.01-1.0 microns) surface layer with porosity of about $5 \%$ and very small pore sizes of 10-65 nm. Mechanical strength is provided by a thick microporous sublayer (porosity of about $80 \%$ ).

We have obtained polymers, based on which asymmetric anisotropic membranes are made in the form of hollow fibres.

PAIs were synthesized based on the TIOC and aromatic diamines of linear (DADPM) and cardio (AF) structures: (PAI-M) and (PAI-TOA) respectively [11]. Pyromellitic acid diimide was investigated as the tetracarboxylic acid imide. PAI was obtained based on of dichloroanhydride pyromellitimido $-\mathrm{N}, \mathrm{N}^{1}$ - dioctic acid (PIOK) and AF: (PAI-POA).

The intramolecular "dilution" of imide cycles by amide "hinges" inside the repetitive structural units of PAI allowed to obtain polymers with improved, compared to polyimides $[17,18]$, solubility in amide solvents and high film-forming ability. The molecular packing density was regulated by varying the macromolecule fragments, which differ in stiffness and lumbar size.

The change in the intrinsic stiffness and the crosssectional dimensions of the PAI macromolecule fragments is reflected in the amount of "kinetic" free volume. "Kinetic" component of free volume $\mathrm{f}^{\mathrm{K}}$ is a right choice in comparison with the "geometric" $f^{\mathrm{G}}$.

By changing the fraction of "kinetic free volume, the gas-separating properties of semi-rigid vitreous polymers are regulated.

As can be seen from Table 1, the gas permeability coefficient $\mathrm{K}$ for cardiac PAI is significantly higher.

Table 1

Gas separation properties of flat membranes

\begin{tabular}{|c|c|c|c|}
\hline PAI & $\mathrm{K}(\mathrm{He})$ & $\mathrm{K}\left(\mathrm{CO}_{2}\right)$ & $\mathrm{K}\left(\mathrm{N}_{2}\right)$ \\
\hline PAI -M & 1.2 & 0.44 & $\ldots$ \\
\hline PAI -TOA & 10.3 & 5.35 & 0.69 \\
\hline PAI -ПOA & 6.0 & 3.54 & 0.65 \\
\hline
\end{tabular}

Studies conducted in cooperation with UkrNDISHW have found that cardiac PAIs and their mixtures with PAI-M meet the requirements for membrane-forming materials.

It is known [19] that one of the means of modifying the chemical structure of PAI is the synthesis of COPAI based on them. As a rule, COPAI have high resistance to oxidative degradation, better physico-chemical properties and technological effectiveness.

The problem of increasing the gas permeability while storing the corresponding selectivity [20-22] was solved due to the fact that as a membrane material COPAI was synthesized based on THIOC, DADPM and AF with different ratios of diamino components.

The obtained COPAIs have the following general formula:

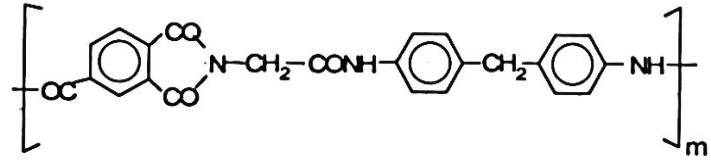<smiles>CC(C)(C)Oc1ccc2c(c1)ON(CC(=O)Nc1ccc(C3(c4ccc(NC5(C)CCC5(C)C)cc4)c4ccccc4-c4ccccc43)cc1)O2</smiles> 
In the SHKDR figures of all COPAIs, the presence of a wide diffuse maximum is an experimental confirmation of their non-crystalline (vitreous) composition. However, asymmetric profiles of amorphous areas show paracrystalline order (probably due to secondary aggregation of self-associative fragments of the chain $[23$, 24]. It can be assumed that the main interchain distance calculated by the standard Bragg equation [24] tend to increase with increasing ratio of AF / DADFM (Table 2).

The slow nature of the ICTR curves suggests the absence of large-scale structural heterogeneities in the samples. However, considering the SHCDR data, this can be explained by the blurring of the electron density differences between the densely packed and leaky microspheres of the COPAI, due to the wide dispersion of their sizes.

A common feature of TGA diagrams for all studied samples is the stepwise nature of the weight loss. Probably less weight loss is associated with the subsequent evaporation of residual moisture and solvent absorbed by the COPAI during the formation of films. In this case, the magnitudes of $\Delta \mathrm{m}_{1}$ and $\Delta \mathrm{m}_{2}$ should correlate with the corresponding number of active sites within the COPAI chains, which presumably involve specific interactions with the water and solvent molecules, respectively.

It can be assumed that carbonyl groups within the dianhydride fragments of the SOPAI chains are the most probable sites of interaction with water molecules through hydrogen bonds. This assumption is in good agreement with $\Delta \mathrm{m}_{1}$ values approximately independent of the composition for all COPAIs (Table 2). Similar electron-donor interactions can be expected between DMAA molecules and arylene units of COPAI. Indeed, $\Delta \mathrm{m}_{2}$ values tend to increase the higher is the AF/DADPM ratio.

The above data can be quantified. Comparing the experimental values of $\Delta \mathrm{ml}$ and $\Delta \mathrm{m}_{2}$ with those theoretically calculated $\Delta \mathrm{m} 1$ and $\Delta \mathrm{m}_{2}$ values, we can conclude that only every fourth/fifth carbonyl group and arylene unit of the recurrent polymeric unit of COPAI participate in specific interaction with water molecules and DMAA, respectively. Assuming that potentially active areas of tightly packed areas are inaccessible to such interactions, the above calculations show that leaky areas contain about $20-25 \%$ of the total volume of the studied PAIs and COPAIs.

The large size and high rigidity of the polymer chain fragments affect, as noted, the density of the molecular package. Small values of packing density, in turn, cause an increase in gas permeability. This is also correlated with the change in the density of polymer solutions (Table 2). Thus, the density gradually decreases from $1.4 \mathrm{~kg} / \mathrm{m}^{3}$ for PAI-M as the content of the cardiovascular component of PAI increases to $0.54 \mathrm{~kg} / \mathrm{m}^{3}$ for PAI-TOA.

COPAI and PAI, characteristic viscosity data, SHKDR and TGA

Table 2

\begin{tabular}{|c|c|c|c|c|c|c|c|}
\hline Samples of polymers & $\begin{array}{c}{[\eta]} \\
\mathrm{kg} / \mathrm{m}^{3}\end{array}$ & $\begin{array}{c}\mathrm{d}_{1} \\
\mathrm{~nm}\end{array}$ & $\begin{array}{c}p \\
\mathrm{~nm}\end{array}$ & $\Delta \mathrm{m}_{1}$ & $\Delta \mathrm{m}_{2}$ & $\Delta \mathrm{m}_{3}$ & $\Delta \mathrm{m}_{4}$ \\
\hline AF/DADFM $=0 / 1$ & 1.4 & 0.55 & 1.18 & 3.8 & 6.6 & 12.5 & 25.0 \\
\hline AF/DADFM $=0 / 3$ & 1.25 & 0.57 & 1.29 & 4.1 & 12.2 & 16.5 & 22.4 \\
\hline AF/DADFM $=1 / 1$ & 1.10 & 0.58 & 1.40 & 2.9 & 14.7 & 13.3 & 19.6 \\
\hline AF/DADFM $=3 / 1$ & 1.05 & 0.59 & 1.50 & 3.1 & 16.8 & 11.9 & 21.2 \\
\hline AF/DADFM $=1 / 0$ & 0.54 & 0.60 & 1.60 & 3.3 & 17.0 & 12.2 & 20.3 \\
\hline
\end{tabular}

Polyamidoimide gas separation membranes are formed mainly from solutions. The study of the properties of the solutions allowed us to determine the existence of polymer concentrations that differentiate the modes of homogeneity and microheterogeneity. The formation of gas separation membranes can be achieved at these "critical" concentrations corresponding to changes in the structure during the transition from diluted to semidiluted solutions.

For diluted solutions of all COPAIs (at a polymer concentration in solution $\mathrm{C} \leq 10 \mathrm{wt} . \%$ ), as well as for the previously studied PAIs [11], the following properties of Newtonian liquids were detected: effective Newtonian viscosity $\eta$ had no dependence on deformation conditions, it did not change with increasing shear rate $\gamma$ at any fixed measurement temperature. The transition to the semi-diluted solution mode ( $\mathrm{C} \geq 15 \mathrm{wt} . \%)$ led to a change in the dependence of $\log \eta=\mathrm{f}(\log \gamma)$ : a decrease in the values of $\eta$ was found with increasing $\gamma$. This indicates a change in the character of the flow of solutions the transition from Newtonian fluids to dilatant.

Indeed, in dependencies $\log \eta=\mathrm{f}(\log \gamma)$ at $\mathrm{C} \geq 15$ wt.\% for all investigated solutions of SOPAI with increasing $\gamma$, there was an increase in the value of $\eta$, then the transition through the plateau and the subsequent decrease in the values of $\eta$ (Fig. 2). This behaviour is particularly clear at high temperatures. This is probably explained, as for PAI solutions, by the emergence of 
temporary intermolecular associates oriented in the direction of motion, which are then destroyed at high shear rates.

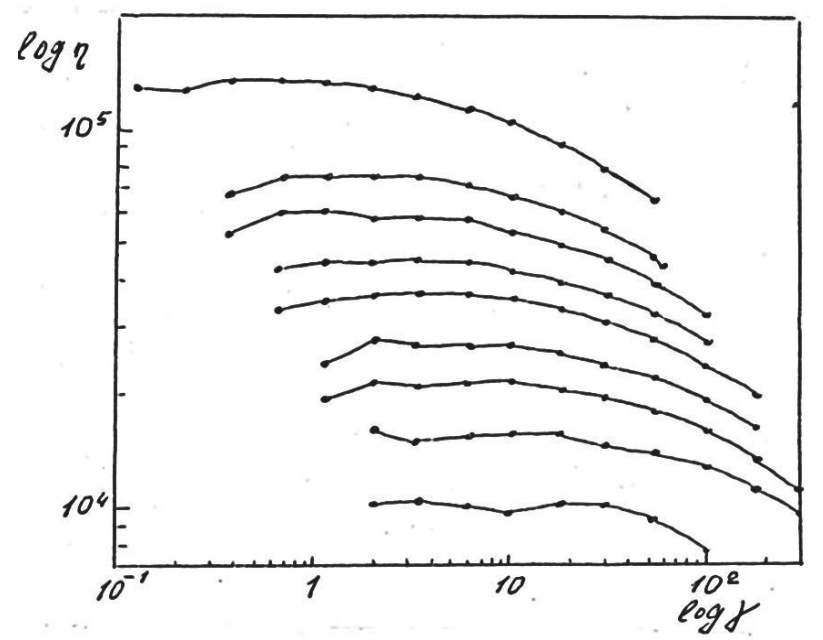

Fig. 2. Dependence of $\log \eta$ on $\log \gamma$ for the COPAI solution with concentration of $20 \mathrm{wt} . \%$.

The transport properties of hollow fibres based on copolyamidoimide are characterized by the following selectivity of $\varphi$ gases and vapours:

$\mathrm{H}_{2} \mathrm{O} / \mathrm{CH}_{4}-2000 ; \mathrm{H}_{2} / \mathrm{N}_{2}-68 ; \mathrm{H}_{2} / \mathrm{CH}_{4}-150 ;$ $\mathrm{CO}_{2} / \mathrm{CH}_{4}-38 ; \mathrm{He} / \mathrm{CO}_{2}-3$;

and permeability $\mathrm{K}$, Barrer $/ \mathrm{cm} 10^{-6}$ :

$\mathrm{H}_{2} \mathrm{O}-1000 ; \mathrm{H}_{2}-7.5 ; \mathrm{He}-5,8 ; \mathrm{CO}_{2}-1.9 ; \mathrm{O}_{2}-0.39$; $\mathrm{N}_{2}-0.11$

The materials of the obtained membranes have high thermal and chemical resistance. After the expiration date, they can be used in electronics and electrical engineering as high quality coating for appliances.

\section{Conclusions}

A method of low-temperature synthesis of soluble COPAI as a membrane material based on dichloroanhydride of THIOC, DADPH and AF was developed.

The presence of "critical" polymer content in the solution is found, which corresponds to the complete saturation of specific interactions between solvent molecules and solvate-active macromolecule chain fragments. The study of the obtained COPAI will allow creating the optimal modes of their processing.

Based on PAI (COPAI), laboratory samples of gasseparation modules, capable of separating hydrogen, helium, carbon dioxide, oxygen, nitrogen, methane and water vapour from mixtures can be made.

\section{References}

[1] Martynov V. V., Ostapenko M. A.: Materialy X Mezhdunarodnoi nauchnoi konferentsiia aspirantov $\mathrm{i}$ stulentov "Okhrana okruzhayushzhei sredy i ratsionalnoe ispolzovanie prirodnykh resursov", Ukraina, Donetsk 2016.

[2] Huliienko S. V.: Modeliuvannia protsesiv membrannoho rozdilennia. KPI im. Ihoria Sikorskoho, Kyiv, 2017, 166 p.

[3] Dytnerskiy Yu. I., Brykov V. P., Kahramanov H. H.: Membrannoe razdelenie hazov. Khimiia, Moskva 1991, $344 \mathrm{p}$.

[4] Novyi spravochnik khimika i tekhnoloha. Protsessy i apparaty khimicheskikh tekhnolohii. Ch. II. SPb. NPO "Professional", Moskva 2006, 916 p.

[5] Mulder M.: Vvedenie $\mathrm{v}$ membrannuyu tekhnolohiyu. Mir, Moskva 1999, 513 p.

[6] Bondarenko V. L., Losyakov N. P., Simonenko Yu. M. a. a.: Vestnik MGTU im. N. E. Baumana. Ser. "Mashinostroenie", 2012. p. 20.

[7] Haraya K., Hakuta K., Obata Y., Shindo N., Itoh K., Wakabaiachi K.: Gas Separation and Purification, 1987, 1, 3.

[8] Barbari T. A., Koros W. J., Paul D. R.: J. Membrane Sci., 1989, 42, p. 69.

[9] Stern S. A., Vaiduanathan R., Prait J. R.: J. Membrane Sci., 1990, 49, p. 1.

[10] Petrenko K. D., Mudrak K. V., Zamulina L. I., Privalko V. P.: Pat. SSSR No. 1699897, opubl. Yanv. 22, 1992.

[11] Mudrak K. V.: Dis. kand. khim. nauk. IKhVS AN USSR, Kiev 1996.

[12] Kesting R. E. (Ed.): Synthetic Polymeric Membranes (2-nd Edition). Wiley, New York 1985.

[13] Koros W. J. (Ed.).: Barrier Polymers and Structures. ACS Symp. Ser. 1990, 423.

[14] Kotov B. V.: ZhFKh, 1988, 62, 2709.

[15] Pedosenko A. V.: Avtoref. dis. ... kand. khim. nauk. IKhVS AN USSR, Kiev 1989.

[16] Petrenko K. D., Zamulina L. I., Pedosenko A. V., Privalko V. P.: Gas Separ. Purif., 1990, 4, 87.

[17] Chin Ping Yang : J. Polym. Sci., 1979, 17, 3255.

[18] Thrunovukkasu A., Nanjan M. I.: J. Polym. Sci.,1983, 15, 855.

[19] Byuler K. U.: Teplo- i termostoykie polimery. Khimiia , Moskva 1984.

[20] Privalko V. P., Mudrak K. V., Usenko A. A., Bening M., Kress I., Shpringer Yu.: VIII Ukrainska konferentsiif po VMS, Ukraina, Kyiv 1996, 195.

[21] C. V. Mudrak., V. P. Privalko a. a.: New Polymeric Materials, 2000, 3, 363.

[22] C. V. Mudrak., V. P. Privalko a. a.: Polym. Adv. Technol., 2003, 14, 96.

[23] V. P. Privalko, A. V. Pedosenko and L. I. Zamulina: Ukr. Polimer. Zh., 1992, 1.

[24] R. Stauga, A. Schoenhals, H.-E. Carius, C. V. Mudrak. and V. P .Privalko: New Polymeric Materials, 1998, 5, 119 . 